\title{
Synthesis and pharmacological evaluation of indole-based sigma receptor ligands
}

\author{
Christophe Mésangeau ${ }^{a}$, Emanuele Amata ${ }^{a}$, Walid Alsharifa ${ }^{a}$, Michael J. Seminerio ${ }^{b}$, \\ Matthew J. Robson ${ }^{\mathrm{b}}$, Rae R. Matsumoto ${ }^{\mathrm{b}}$, Jacques H. Poupaert ${ }^{\mathrm{c}}$, and Christopher R. \\ McCurdy ${ }^{\mathrm{a}}$ \\ aDepartment of Medicinal Chemistry, School of Pharmacy, The University of Mississippi, \\ University, Mississippi 38677, USA

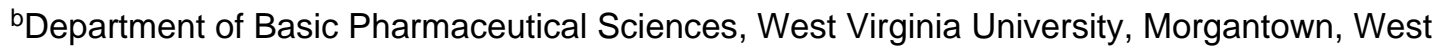 \\ Virginia 26506, USA \\ 'Université Catholique de Louvain, 74 Avenue Emmanuel Mounier, B-1200 Brussels, Belgium
}

\begin{abstract}
A series of novel indole-based analogues were prepared and their affinities for sigma receptors were determined using in vitro radioligand binding assays. The results of this study identified several compounds with nanomolar sigma-2 affinity and significant selectivity over sigma-1 receptors. In particular, 2-(4-(3-(4-fluorophenyl)indol-1-yl)butyl)-6,7-dimethoxy-1,2,3,4tetrahydroisoquinoline (9f) was found to display high affinity at sigma-2 receptors with good selectivity $(\sigma-1 / \sigma-2=395)$. The pharmacological binding profile for this compound was established with other relevant nonsigma sites.
\end{abstract}

\section{Keywords}

Sigma-2 receptors; indole

\section{Introduction}

Sigma receptors are classified into two subtypes denoted sigma-1 and sigma-2. [1] The sigma-1 receptor has been purified and cloned in several species and is well characterized at the functional and structural level [2,3]. It is expressed in the central nervous system and is also widely distributed in peripheral organs and tissues such as heart and spleen [4]. The sigma-2 receptor suffers from a lower degree of knowledge, in part because this protein has not yet been cloned. These receptors are associated with functions and disorders such as inflammation [5], depression [6,7], anxiety [8], Alzheimer's disease [9], epilepsy and drug abuse [10-12]. Cancer diagnosis and treatment is also an area of great interest in current sigma receptor research. Indeed sigma receptor overexpression in malignant tissues suggest that tumors may be visualized by SPECT or PET imaging using radiolabeled sigma ligands

(C) 2011 Elsevier Masson SAS. All rights reserved.

Corresponding Author: Christopher R. McCurdy, Ph.D., R.Ph., Associate Professor of Medicinal Chemistry and Pharmacology, Department of Medicinal Chemistry, School of Pharmacy, The University of Mississippi, University, MS 38677, Phone: 1-662-915-5882, Fax: 1-662-915-5638, cmccurdy@olemiss.edu.

Publisher's Disclaimer: This is a PDF file of an unedited manuscript that has been accepted for publication. As a service to our customers we are providing this early version of the manuscript. The manuscript will undergo copyediting, typesetting, and review of the resulting proof before it is published in its final citable form. Please note that during the production process errors may be discovered which could affect the content, and all legal disclaimers that apply to the journal pertain. 
[13-16]. The sigma-2 subtype is upregulated in proliferative cells where the density of sigma-2 receptors was found to be 10-fold higher than in quiescent cells [17]. Additional studies have shown that sigma ligands, especially sigma-2 agonists, can inhibit proliferation and induce apoptosis in tumor cells which give sigma ligands possible application as agents for the treatment of cancer $[18,19]$. Therefore, the finding of selective sigma-2 receptor ligands may aid in the isolation and characterization of this receptor, but also could lead to the development of new therapeutics, particularly in oncology.

Several classes of structurally diverse compounds have been shown to possess a high affinity for sigma receptors (for a review see Narayanan et al. [20]). While several selective, high-affinity sigma-1 ligands are available [21-25], potent sigma-2 receptor selective ligands are less common. Siramesine (Lu28-179, $\sigma-1=17 \mathrm{nM}, \sigma-2=0.12 \mathrm{nM})$ and 5bromo- $N$-(4-(6,7-dimethoxy-3,4-dihydroisoquinolin-2(1H)-yl)butyl)-2,3-

dimethoxybenzamide $(\sigma-1=12,900 \mathrm{nM}, \sigma-2=8.2 \mathrm{nM})$ are two of the most highly selective sigma-2 ligands identified to date $[26,27]$.

In our previous work we reported the synthesis and biological evaluation of a series of benzoazoles with high, mixed affinity for sigma-1 and sigma-2 receptors [28]. Among the compounds described in this early study, 3-(4-(4-cyclohexylpiperazin-1-

yl)butyl)benzo[d]thiazol-2(3H)-one (1) exhibited a subnanomolar sigma-2 affinity and a modest preference for sigma-2 versus sigma-1 with a selectivity ratio of 11 (Figure 1). The goal of the present study was to prepare novel sigma ligands with selectivity for sigma-2 and we decided to use this compound as our lead structure.

\section{Results and discussion}

\subsection{Chemistry}

The strategy we chose involved the replacement of the benzothiazole heterocycle of $\mathbf{1}$ by the more stable and versatile indole ring (Figure 1). Several parts of the new molecule $\mathbf{4 a}$ were then modified to develop new indole-based sigma receptor ligands. These modifications were made at three different positions: an acetyl group was introduced at the 5 position of the indole ring, the 1-cyclohexylpiperazine (A-ring, Figure 2) was replaced by other cyclic amines (B- and $\mathbf{C}$-ring) and finally different aryl groups (D-, E- and F-rings) were introduced at the 3 position of the heterocycle.

The introduction of an acetyl group on the 5 position of the indole was motivated by previous work in our laboratory in the benzoazole series (data not shown) which hinted at this group giving better sigma-2 selectivity. Similarly, we decided to replace the piperazine group of $\mathbf{4 a}$ by two cyclic amines that were described in the literature as potentially sigma- 2 preferring and gave good results selectivity-wise in the benzoazole series: 1-(4-

fluorophenyl)piperazine (Bring) and 6,7-dimethoxy-1,2,3,4-tetrahydroisoquinoline (C-ring) [27]. Furthermore, the decision to introduce an aryl group in the C-3 indole position was inspired by the work of Perregaard who successfully converted a 3-(aminobutyl)indole with mixed affinity for sigma receptors to the sigma- 2 selective ligand siramesine by adding a 4fluorophenyl ring in the NH position of the indole [26]. The aryl groups we chose were the unsubstituted phenyl group (D-ring), the metabolically more stable 4-fluorophenyl ring (Ering), and the H-bond acceptor and phenyl-bioisostere furan ring (F-ring).

The preparation of compounds $\mathbf{4 a - 4 f}$ is outlined in Scheme 1. Treatment of indole (2a) or 5acetyl-indole (2b) with 1,4-dibromobutane in the presence of potassium hydroxide in DMF gave the bromo derivatives $\mathbf{3 a}-\mathbf{3 b}$. These were then coupled with 1-cyclohexylpiperazine (A-ring, Figure 2), 1-(4-fluorophenyl)piperazine (B-ring) or 6,7-dimethoxy-1,2,3,4- 
tetrahydroisoquinoline (C-ring) in the presence of potassium carbonate in DMF to afford target compounds $\mathbf{4 a - 4 f}$.

The synthesis of final compounds 9a-9i is described in Scheme 2. Intermediates 6a-6c were prepared with excellent yields by reaction of commercially available 3-bromo-1(phenylsulfonyl)indole (5) with the appropriate boronic acid under Suzuki conditions [29]. Indoles 6a-6c underwent an easy and clean deprotection with magnesium and ammonium chloride in methanol to give the corresponding derivatives 7a-7c. $N$-alkylation of the heterocyles with 1,4-dibromobutane gave the bromo intermediates 8a-8c which were then reacted with A-, B- and $\mathbf{C}$-ring to give 3-substituted-indole derivatives $\mathbf{9 a - 9 i}$.

\subsection{Pharmacology}

All final compounds were tested for in vitro affinity at sigma- 1 and sigma- 2 receptors using well-established assay conditions [30-34]. The sigma-1 receptors were labeled with $5 \mathrm{nM}$ $\left[{ }^{3} \mathrm{H}\right](+)$-pentazocine and the sigma-2 receptors were labeled with $3 \mathrm{nM}\left[{ }^{3} \mathrm{H}\right] \mathrm{di}-\mathrm{o}-$ tolylguanidine (DTG) in the presence of $300 \mathrm{nM}(+)$-pentazocine to block sigma-1 receptors. Non-specific binding was determined in the presence of $10 \mu \mathrm{M}$ haloperidol. Ten concentrations of each sigma compound (0.1-1000 nM) were used in the assays. The chemical structures, sigma binding affinities and selectivity ratios of the new compounds are summarized in Table 1. In addition, the affinity of $\mathbf{9 f}$ for monoamine transporters and several serotonin and dopamine receptors was determined. A binding profile of the compound was also prepared by NovaScreen/Caliper Life Sciences (Hanover, MD). The results of these experiments are summarized in Tables 2 and 3.

As shown in Table 1, the lead compound $\mathbf{1}$ had a high affinity for sigma-1 and sigma-2 receptors (4.17 and $0.39 \mathrm{nM}$, respectively) and a small selectivity for sigma-2 versus sigma-1 receptors $(\sigma-1 / \sigma-2=10.7)$. The replacement of the benzothiazolone core by an indole core resulted in no change in affinity for sigma-1 receptors and a slight decrease in affinity for sigma-2. As a result, 4 a does not exhibit a preference for sigma-2 receptors, but this decrease in selectivity is not significant, while the change of the central template gives us access to a whole new class of potent sigma ligands. The next step was the replacement of the piperazine moiety with two different putative sigma-2 preferring elements $(\mathbf{B}$ - and $\mathbf{C}$ ring). The 1-(4-fluorophenyl)piperazine compound $\mathbf{4 b}$ showed only a slight selectivity ( $\sigma-1 /$ $\sigma-2$ ratio of 5) while the 6,7-dimethoxy-1,2,3,4-tetrahydroisoquinoline derivative $\mathbf{4 c}$ exhibited an interesting selectivity of 38 along with a high affinity for the sigma- 2 receptor $\left(K_{\mathrm{i}}=3.66 \mathrm{nM}\right)$. Introduction of an acetyl group in the C-5 position of the indole provided compounds (4d-4f) with high affinities for both sigma receptors, but no meaningful selectivity. Compounds 9a-9i were subsequently prepared to examine the influence of various aryl cycles attached in position 3 of the indole and, as depicted in Table 1, these pharmacomodulations gave mixed results. Generally most of the compounds displayed decreased affinities for both sigma receptors and a small selectivity. However 6,7dimethoxy-1,2,3,4-tetrahydroisoquinolines 9 f and $\mathbf{9 i}$ proved to be potent and selective sigma-2 selective ligands. In particular, compound 9 f with a 4-fluorophenyl ring in the C-3 position of its core ring presented a high affinity for the sigma-2 receptor $(7.45 \mathrm{nM})$ and a weak affinity of $2948 \mathrm{nM}$ for the sigma-1 receptor, giving this indole one of the best sigma-1/sigma-2 selectivity ratios $(\sigma-1 / \sigma-2=395)$ described so far. Because many ligands for sigma receptors also bind to non-sigma sites, we decided to submit $9 f$ to an extensive selectivity profile characterization. As can be seen from Table 2, compound $\mathbf{9 f}$ had essentially no affinity for dopamine and norepinephrine transporters and a low affinity for serotonin transporters. It also showed no measurable affinity for the $\mathrm{D}_{1}$ receptor and very low affinities for dopaminergic receptors $\mathrm{D}_{2}$ and $\mathrm{D}_{3}$ and serotoninergic receptors 5- $\mathrm{HT}_{1 \mathrm{~A}}$ and $5-\mathrm{HT}_{2 \mathrm{~A}}$. The compound was then tested by NovaScreen in 64 radioligand/enzyme assays (neurotransmitter related, steroids, ion channels, second messengers, prostaglandins, 
growth factors/hormones, brain/gut peptides, enzymes) at two concentrations of $10^{-5} \mathrm{M}$ and $10^{-7} \mathrm{M}$. The summary of this "profiling" is presented in Table 3. A radioligand displacement of more than $50 \%$ was observed in 16 assays at the concentration of $10^{-5} \mathrm{M}$ and in only the glycine, strychnine-sensitive assay at the concentration of $10^{-7} \mathrm{M}$. This compound seems to be a reasonably clean sigma- 2 selective ligand and therefore could be of great interest as a lead for further development or as a pharmacological tool.

\section{Conclusion}

We synthesized a series of 4-(indol-1-yl)butan-1-amines and evaluated their binding affinity for sigma receptors. Several high-affinity sigma-2 receptor ligands with significant selectivity for sigma- 2 versus sigma- 1 were identified. The best result was obtained with the ligand bearing a 4-fluorophenyl ring in the $\mathrm{C}-3$ position of its indole core and a 6,7dimethoxy-1,2,3,4-tetrahydroisoquinoline as the distal cyclic amine. This compound, which displayed a high affinity for the sigma-2 receptor $(7.45 \mathrm{nM})$ and a weak affinity for the sigma-1 receptor (2948 $\mathrm{nM}$ ), was also submitted to an extensive selectivity profile characterization and only exhibited moderate affinity for the glycine, strychnine-sensitive assay at the $10^{-7} \mathrm{M}$ concentration.

\section{Experimental protocols}

\subsection{Chemistry}

Reagents and starting materials were obtained from commercial suppliers and were used without purification. Precoated silica gel GF Uniplates from Analtech were used for thinlayer chromatography (TLC). Column chromatography was performed on silica gel 60 (Sorbent Technologies). Melting points were determined on a Electrothermal 9100 apparatus and are uncorrected. ${ }^{1} \mathrm{H}$ and ${ }^{13} \mathrm{C}$ NMR spectra were obtained on a Bruker $500 \mathrm{MHz}$, $400 \mathrm{MHz}$, or Bruker $400 \mathrm{MHz}$ Ultra Shield. The high resolution mass spectra (HRMS) were recorded on a Waters Micromass Q-Tof Micro mass spectrometer with a lock spray source. The mass spectra (MS) were recorded on a WATERS ACQUITY Ultra Performance LC with ZQ detector in ESI or APCI mode. Elemental analysis $(\mathrm{C}, \mathrm{H}, \mathrm{N})$ were recorded on an elemental analyzer, Perkin-Elmer CHN/SO Series II Analyzer. Chemical names were generated using ChemDraw Ultra (CambridgeSoft, version 10.0). Except where otherwise noted, ${ }^{1} \mathrm{H}$ and ${ }^{13} \mathrm{C}$ NMR data for final compounds are given for materials in their salt form.

\subsubsection{General procedure for the synthesis of 1-(4-bromobutyl)indole and} derivatives (3a, $3 \mathbf{b}$ and $\mathbf{8 a - 8 c})$ - The method adopted for the synthesis of 1-(4bromobutyl)indole (3a) is described. Potassium hydroxyde ( $3.83 \mathrm{~g}, 68.3 \mathrm{mmol})$ and tetrabutylammonium iodide $(0.2 \mathrm{~g}, 0.54 \mathrm{mmol})$ were added, under mechanical stirring, to a solution of indole (2a) $(2 \mathrm{~g}, 17.1 \mathrm{mmol})$ in anhydrous DMF $(25 \mathrm{~mL})$. The reaction mixture was stirred at room temperature for $45 \mathrm{~min}$. and cooled to $0^{\circ} \mathrm{C}$. 1,4-Dibromobutane was then added and the mixture was stirred for $15 \mathrm{~min}$. at $0^{\circ} \mathrm{C}$ and for $1 \mathrm{~h}$ at room temperature. The mixture was poured into $70 \mathrm{~mL}$ of water, extracted with methylene chloride $(3 \times 50 \mathrm{~mL})$, and the combined organic layers were washed with brine and dried. The solvent was removed in vacuo, and the residue was chromatographed on a silica gel column using a gradient of hexanes/ethyl acetate (10:0 to 9:1) as the eluent to give $2.92 \mathrm{~g}(68 \%)$ of 1-(4bromobutyl)indole as a pale yellow oil. ${ }^{1} \mathrm{H}$ NMR $\left(400 \mathrm{MHz}, \mathrm{CDCl}_{3}\right): \delta 7.72(\mathrm{~d}, J=7.8 \mathrm{~Hz}$, $1 \mathrm{H}), 7.39(\mathrm{~d}, J=8.2 \mathrm{~Hz}, 1 \mathrm{H}), 7.29(\mathrm{t}, J=7.2 \mathrm{~Hz}, 1 \mathrm{H}), 7.19(\mathrm{t}, J=7.7 \mathrm{~Hz}, 1 \mathrm{H}), 7.12(\mathrm{~d}, J=$ $3.0 \mathrm{~Hz}, 1 \mathrm{H}), 6.58(\mathrm{~d}, J=2.9 \mathrm{~Hz}, 1 \mathrm{H}), 4.15(\mathrm{t}, J=6.8 \mathrm{~Hz}, 2 \mathrm{H}), 3.38(\mathrm{t}, J=6.5 \mathrm{~Hz}, 2 \mathrm{H}), 2.02$ (quint, $J=7.3 \mathrm{~Hz}, 2 \mathrm{H}), 1.86$ (quint, $J=7.0 \mathrm{~Hz}, 2 \mathrm{H}) .{ }^{13} \mathrm{C} \mathrm{NMR}\left(100 \mathrm{MHz}, \mathrm{CDCl}_{3}\right): \delta$ 127.75, 127.69, 121.63, 121.15, 119.47, 109.39, 101.43, 101.37, 45.54, 33.20, 30.06, 28.91. MS (ESI) $m / z, 252[\mathrm{M}+\mathrm{H}]^{+}$for ${ }^{79} \mathrm{Br}, 254[\mathrm{M}+\mathrm{H}]^{+}$for ${ }^{81} \mathrm{Br}$. 
4.1.2. 1-[1-(4-Bromobutyl)indol-5-yl]-ethanone (3b)-This compound was prepared from 5-acetylindole (2b) as described for 3a. $67 \%$ yield, white solid. mp $67-68{ }^{\circ} \mathrm{C} .{ }^{1} \mathrm{H}$ NMR $\left(400 \mathrm{MHz}, \mathrm{CDCl}_{3}\right) \delta 8.31(\mathrm{~s}, 1 \mathrm{H}), 7.90(\mathrm{~d}, J=8.7,1 \mathrm{H}), 7.35(\mathrm{~d}, J=8.7,1 \mathrm{H}), 7.16(\mathrm{~d}$, $J=3.0,1 \mathrm{H}), 6.63(\mathrm{~d}, J=3.1,1 \mathrm{H}), 4.18(\mathrm{t}, J=5.3,2 \mathrm{H}), 3.38(\mathrm{t}, J=6.4,2 \mathrm{H}), 2.67(\mathrm{~s}, 3 \mathrm{H})$, $2.05-2.00(\mathrm{~m}, 2 \mathrm{H}), 1.87-1.80(\mathrm{~m}, 3 \mathrm{H}) .{ }^{13} \mathrm{C}$ NMR $\left(100 \mathrm{MHz}, \mathrm{CDCl}_{3}\right) \delta 198.21,138.44$, 129.59, 129.20, 128.06, 123.39, 121.89, 109.13, 103.41, 45.72, 32.79, 29.84, 28.83, 26.61. MS (ESI) $\mathrm{m} / z 316[\mathrm{M}+\mathrm{Na}]^{+}$for ${ }^{79} \mathrm{Br}, 318[\mathrm{M}+\mathrm{Na}]^{+}$for ${ }^{81} \mathrm{Br}$.

4.1.3. General procedure for the synthesis of 1-(4-(4-cyclohexylpiperazin-1yl)butyl)indole and other final products (4a-4f, 9a-9i)-The method adopted for the synthesis of 1-(4-(4-cyclohexylpiperazin-1-yl)butyl)indole dioxalate (4a) is described. $\mathrm{K}_{2} \mathrm{CO}_{3}(0.2 \mathrm{~g}, 1.43 \mathrm{mmol})$ and 1-cyclohexylpiperazine $(0.081 \mathrm{~g}, 0.47 \mathrm{mmol})$ were added, under mechanical stirring, to a solution of $\mathbf{3 a}(0.12 \mathrm{~g}, 0.47 \mathrm{mmol})$ in anhydrous DMF (4 $\mathrm{mL}$ ). The reaction mixture was heated at $60^{\circ} \mathrm{C}$ for $2 \mathrm{~h}$. After cooling, the mixture was poured into $20 \mathrm{~mL}$ of water, extracted with ethyl acetate $(3 \times 30 \mathrm{~mL})$, and the combined organic layers were washed with saturated aqueous $\mathrm{NaCl}$ and dried. The solvent was removed in vacuo, and the residue was chromatographed on a silica gel column using methylene chloride/methanol (97:3) as the eluent. 1-(4-(4-cyclohexylpiperazin-1yl)butyl)indole was isolated as a dioxalate salt (white solid, $0.073 \mathrm{~g}, 30 \%$ ). $\mathrm{mp} 230-233$ ${ }^{\circ} \mathrm{C} .{ }^{1} \mathrm{H}$ NMR (400 MHz, DMSO- $\left.d_{6}, 60^{\circ} \mathrm{C}\right): \delta 7.55(\mathrm{br} \mathrm{s}, 4 \mathrm{H}), 7.53(\mathrm{~d}, J=7.9 \mathrm{~Hz}, 1 \mathrm{H}), 7.45$ $(\mathrm{d}, J=8.2 \mathrm{~Hz}, 1 \mathrm{H}), 7.33(\mathrm{~d}, J=3.0 \mathrm{~Hz}, 1 \mathrm{H}), 7.12(\mathrm{t}, J=7.4 \mathrm{~Hz}, 1 \mathrm{H}), 7.00(\mathrm{t}, J=7.4 \mathrm{~Hz}$, $1 \mathrm{H}), 6.42(\mathrm{~d}, J=2.8 \mathrm{~Hz}, 1 \mathrm{H}), 4.18(\mathrm{t}, J=6.9 \mathrm{~Hz}, 2 \mathrm{H}), 3.00(\mathrm{~s}, 4 \mathrm{H}), 2.83-2.77(\mathrm{~m}, 5 \mathrm{H}), 2.57$ $(\mathrm{t}, J=7.3 \mathrm{~Hz}, 2 \mathrm{H}), 1.95-1.93(\mathrm{~m}, 2 \mathrm{H}), 1.83-1.78(\mathrm{~m}, 4 \mathrm{H}), 1.61-1.58(\mathrm{~m}, 1 \mathrm{H}), 1.52-1.47(\mathrm{~m}$, $2 \mathrm{H}), 1.35-1.19(\mathrm{~m}, 4 \mathrm{H}), 1.13-1.07(\mathrm{~m}, 1 \mathrm{H}) .{ }^{13} \mathrm{C}$ NMR (100 MHz, DMSO- $\left.d_{6}, 60^{\circ} \mathrm{C}\right): \delta$ $162.58,135.49,128.16,127.95,120.64,120.14,118.54,109.42,100.22,63.20,55.54$, 49.78, 46.85, 44.91, 27.00, 26.65, 24.2, 24.38, 22.23. Anal. calcd for $\mathrm{C}_{26} \mathrm{H}_{37} \mathrm{~N}_{3} \mathrm{O}_{8}$ : C, 60.10; H, 7.18; N, 8.09. Found: C, 60.58; H, 6.80; N, 8.09. HRMS (TOF ES+) calcd for $\mathrm{C}_{22} \mathrm{H}_{34} \mathrm{~N}_{3}$ $[\mathrm{M}+\mathrm{H}]^{+} 340.2753$, found 340.2759 .

4.1.4. 1-(4-(4-(4-Fluorophenyl)piperazin-1-yl)butyl)indole oxalate (4b)-This compound was prepared from 3a and 1-(4-fluorophenyl)piperazine as described for $\mathbf{4 a}$. $25 \%$ yield, white solid. mp 160-162 ${ }^{\circ} \mathrm{C} .{ }^{1} \mathrm{H}$ NMR $\left(400 \mathrm{MHz}\right.$, DMSO- $\left.d_{6}\right): \delta 7.54(\mathrm{~d}, J=7.8 \mathrm{~Hz}$, $1 \mathrm{H}), 7.48(\mathrm{~d}, J=8.1 \mathrm{~Hz}, 1 \mathrm{H}), 7.13-6.98(\mathrm{~m}, 6 \mathrm{H}), 6.42(\mathrm{~s}, 1 \mathrm{H}), 4.21-4.18(\mathrm{~m}, 2 \mathrm{H}), 3.27-2.95$ $(\mathrm{m}, 10 \mathrm{H}), 1.78-1.63(\mathrm{~m}, 4 \mathrm{H}) .{ }^{13} \mathrm{C}$ NMR $\left(100 \mathrm{MHz}, \mathrm{DMSO}-d_{6}\right): \delta 164.38,156.47(J=236.0$ $\mathrm{Hz}), 146.73,135.58,128.59,128.15,118.91,117.67(J=7.1 \mathrm{~Hz}), 115.43(J=22.0 \mathrm{~Hz})$, 109.75, 100.54, 55.29, 50.97, 46.67, 44.94, 27.09, 21.16. Anal. calcd for $\mathrm{C}_{24} \mathrm{H}_{28} \mathrm{FN}_{3} \mathrm{O}_{4} \cdot{ }^{1 / 4}$ $\mathrm{H}_{2} \mathrm{O}: \mathrm{C}, 64.63 ; \mathrm{H}, 6.44 ; \mathrm{N}, 9.42$. Found: C, 64.60; H, 6.05; N, 9.32. HRMS (TOF ES+) calcd for $\mathrm{C}_{22} \mathrm{H}_{27} \mathrm{~N}_{3} \mathrm{~F}[\mathrm{M}+\mathrm{H}]^{+} 352.2189$, found 352.2206.

\subsubsection{2-(4-(Indol-1-yl)butyl)-6,7-dimethoxy-1,2,3,4-tetrahydroisoquinoline} oxalate (4c)-This compound was prepared from 3a and 6,7-dimethoxy-1,2,3,4tetrahydroisoquinoline as described for 4a. $51 \%$ yield, white solid. mp $186-187{ }^{\circ} \mathrm{C} .{ }^{1} \mathrm{H}$ NMR (400 MHz, DMSO- $\left.d_{6}\right): \delta 11.57$ (br s, $\left.2 \mathrm{H}\right), 7.55$ (d, $\left.J=7.8 \mathrm{~Hz}, 1 \mathrm{H}\right), 7.49$ (d, $J=8.2$ $\mathrm{Hz}, 1 \mathrm{H}), 7.38(\mathrm{~d}, J=3.0 \mathrm{~Hz}, 1 \mathrm{H}), 7.13(\mathrm{t}, J=7.3 \mathrm{~Hz}, 1 \mathrm{H}), 7.02(\mathrm{t}, J=7.4 \mathrm{~Hz}, 1 \mathrm{H}), 6.76(\mathrm{~s}$, $1 \mathrm{H}), 6.73(\mathrm{~s}, 1 \mathrm{H}), 6.43(\mathrm{~d}, J=2.8 \mathrm{~Hz}, 1 \mathrm{H}), 4.20(\mathrm{t}, J=6.6 \mathrm{~Hz}, 2 \mathrm{H}), 4.13(\mathrm{~s}, 2 \mathrm{H}), 3.72(\mathrm{~s}$, $3 \mathrm{H}), 3.71(\mathrm{~s}, 3 \mathrm{H}), 3.31-3.29(\mathrm{~m}, 2 \mathrm{H}), 3.10-3.06(\mathrm{~m}, 2 \mathrm{H}), 2.93-2.91(\mathrm{~m}, 2 \mathrm{H}), 1.83-1.71(\mathrm{~m}$, 4H). ${ }^{13} \mathrm{C}$ NMR (100 MHz, DMSO- $\left.d_{6}\right): \delta 164.62,148.16,147.57,135.57,128.60,128.15$, $123.55,120.99,120.66,120.44,118.91,111.49,109.77,109.76,100.53,55.55,55.48$, $54.48,51.61,48.83,44.93,27.03,24.65,21.21$. HRMS (TOF ES+) calcd for $\mathrm{C}_{23} \mathrm{H}_{29} \mathrm{~N}_{2} \mathrm{O}_{2}$ $[\mathrm{M}+\mathrm{H}]^{+}$365.2229, found 365.2242. 
4.1.6. 1-\{1-[4-(4-Cyclohexyl-piperazin-1-yl)-butyl]indol-5-yl\}-ethanone dioxalate (4d)-This compound was prepared from $\mathbf{3 b}$ and 1-cyclohexylpiperazine as described for 4a. $31 \%$ yield, white solid. $\mathrm{mp} 224-227{ }^{\circ} \mathrm{C} .{ }^{1} \mathrm{H}-\mathrm{NMR}$ (free amine, $400 \mathrm{MHz}, \mathrm{CDCl}_{3}$ ): $\delta$ $8.16(\mathrm{~d}, J=\mathrm{Hz}, 1 \mathrm{H}), 7.74(\mathrm{t}, J=8.1 \mathrm{~Hz}, 1 \mathrm{H}), 7.23(\mathrm{t}, J=8.5 \mathrm{~Hz}, 1 \mathrm{H}), 7.06-7.03(\mathrm{~m}, 1 \mathrm{H})$, 6.48-6.45 (m, 1H), 4.04-3.99 (m, 2H), $2.63(\mathrm{~s}, 4 \mathrm{H}), 2.53-2.51(\mathrm{~m}, 3 \mathrm{H}), 2.45(\mathrm{~s}, 4 \mathrm{H}), 2.45(\mathrm{~s}$, $1 \mathrm{H}), 2.26-2.21(\mathrm{~m}, 2 \mathrm{H}), 1.85(\mathrm{~s}, 2 \mathrm{H}), 1.73-1.70(\mathrm{~m}, 4 \mathrm{H}), 1.52(\mathrm{~d}, J=10.0 \mathrm{~Hz}, 1 \mathrm{H})$, 1.37-1.35 (m, 2H), 1.14-1.13 (m, 4H), 1.03-0.99 (s, 1H). ${ }^{13} \mathrm{C}$ NMR (100 MHz, free amine, $\left.\mathrm{CDCl}_{3}\right) \delta 198.09,138.33,129.46,129.27,127.94,123.23,121.53,109.25,103.00,64.08$, $57.19,51.83,48.37,46.29,27.96,27.79,26.56,25.69,25.43,23.74$. Anal. calc. for $\mathrm{C}_{28} \mathrm{H}_{39} \mathrm{~N}_{3} \mathrm{O}_{9}$ : C, 59.88; H, 7.00; N, 7.48. Found: C, 59.54; H, 6.83; N, 7.60. HRMS (TOF $\mathrm{ES}+$ ) calcd for $\mathrm{C}_{24} \mathrm{H}_{36} \mathrm{~N}_{3} \mathrm{O}[\mathrm{M}+\mathrm{H}]^{+} 382.2858$, found 382.2875.

\subsubsection{1-(1-\{4-[4-(4-Fluorophenyl)-piperazin-1-yl]-butyl\}indol-5-yl)-ethanone} dioxalate (4e)-This compound was prepared from $3 \mathbf{b}$ and 1-(4-fluorophenyl)piperazine as described for 4a. $37 \%$ yield, white solid. mp $140-142{ }^{\circ} \mathrm{C} .{ }^{1} \mathrm{H}$ NMR (free amine, 400 MHz, DMSO- $\left.d_{6}\right) \delta 8.28(\mathrm{~s}, 1 \mathrm{H}), 7.76(\mathrm{~d}, J=8.7 \mathrm{~Hz}, 1 \mathrm{H}), 7.56(\mathrm{~d}, J=8.7 \mathrm{~Hz}, 1 \mathrm{H}), 7.49$ (d, $J$ $=3.0 \mathrm{~Hz}, 1 \mathrm{H}), 7.00(\mathrm{t}, J=8.9 \mathrm{~Hz}, 2 \mathrm{H}), 6.87(\mathrm{dd}, J=8.3,5.4 \mathrm{~Hz}, 2 \mathrm{H}), 6.61(\mathrm{~d}, J=2.5 \mathrm{~Hz}$, $1 \mathrm{H}), 4.21(\mathrm{t}, J=6.9 \mathrm{~Hz}, 2 \mathrm{H}), 2.98(\mathrm{~s}, 4 \mathrm{H}), 2.58(\mathrm{~s}, 3 \mathrm{H}), 2.39(\mathrm{~s}, 4 \mathrm{H}), 2.26(\mathrm{t}, J=7.1 \mathrm{~Hz}$, $2 \mathrm{H}$ ), $1.87-1.64(\mathrm{~m}, 2 \mathrm{H}), 1.39(\mathrm{~d}, J=7.0 \mathrm{~Hz}, 2 \mathrm{H}) .{ }^{13} \mathrm{C}$ NMR (free amine, $100 \mathrm{MHz}$, DMSO$\left.d_{6}\right) \delta 197.82,156.39(J=234.0 \mathrm{~Hz}), 148.37,138.57,130.92,129.29,128.01,123.30$, $121.38,117.41$ (d, $J=7.6 \mathrm{~Hz}), 115.64(\mathrm{~d}, J=21.8 \mathrm{~Hz}), 110.22,102.98,57.46,53.05,49.40$, 46.03, 40.42, 40.21, 40.00, 39.59, 28.13, 27.02, 23.84. Anal. calc. for $\mathrm{C}_{28} \mathrm{H}_{32} \mathrm{FN}_{3} \mathrm{O}_{9} \cdot 5 / 4 \mathrm{H}_{2} \mathrm{O}$ : C, 56.42; H, 5.79; N, 7.10. Found: C, 56.41; H, 5.83; N, 7.05. HRMS (TOF ES+) calcd for $\mathrm{C}_{24} \mathrm{H}_{29} \mathrm{~N}_{3} \mathrm{OF}[\mathrm{M}+\mathrm{H}]^{+} 394.2295$, found 394.2290.

\subsubsection{1-\{1-[4-(6,7-Dimethoxy-3,4-dihydro-1H-isoquinolin-2-yl)-butyl]indol-5-yl\}- ethanone oxalate (4f)-This compound was prepared from $3 \mathbf{b}$ and 6,7 -}

dimethoxy-1,2,3,4-tetrahydroisoquinoline as described for $\mathbf{4 a} .41 \%$ yield, white solid. $\mathrm{mp}$ $170-171{ }^{\circ} \mathrm{C} .{ }^{1} \mathrm{H}$ NMR (free amine, $\left.400 \mathrm{MHz}, \mathrm{CDCl}_{3}\right) \delta 8.29(\mathrm{~s}, 1 \mathrm{H}), 7.86(\mathrm{~d}, J=8.7 \mathrm{~Hz}$, $1 \mathrm{H}), 7.35(\mathrm{~d}, J=8.7 \mathrm{~Hz}, 1 \mathrm{H}), 7.17(\mathrm{~s}, 1 \mathrm{H}), 6.59(\mathrm{~d}, J=10.8 \mathrm{~Hz}, 2 \mathrm{H}), 6.48(\mathrm{~s}, 1 \mathrm{H}), 4.19-4.15$ $(\mathrm{m}, 3 \mathrm{H}), 3.82-3.81(\mathrm{~m}, 6 \mathrm{H}), 3.48(\mathrm{~s}, 2 \mathrm{H}), 2.79-2.76(\mathrm{~m}, 2 \mathrm{H}), 2.64(\mathrm{~s}, 3 \mathrm{H}), 2.50-2.47(\mathrm{~m}$, $2 \mathrm{H}), 1.94-1.90(\mathrm{~m}, 2 \mathrm{H}), 1.61-1.59(\mathrm{~m}, 3 \mathrm{H}), 1.28-1.25(\mathrm{~m}, 2 \mathrm{H}) .{ }^{13} \mathrm{C}$ NMR (free amine, 100 $\left.\mathrm{MHz}, \mathrm{CDCl}_{3}\right) \delta 198.20,162.50,147.42,138.47,129.40,128.00,126.00,123.28,121.66$, 111.37, 109.47, 109.26, 103.07, 57.26, 55.90, 55.44, 50.79, 46.40, 36.42, 31.37, 28.09, 26.56, 24.28. Anal. calc. for $\mathrm{C}_{27} \mathrm{H}_{32} \mathrm{~N}_{2} \mathrm{O}_{7} \cdot \mathrm{H}_{2} \mathrm{O}$ : C, 63.02; H, 6.66; N, 5.44. Found: C, 63.26; $\mathrm{H}, 6.15$; N, 5.46. HRMS (TOF ES+) calcd for $\mathrm{C}_{25} \mathrm{H}_{31} \mathrm{~N}_{2} \mathrm{O}_{3}[\mathrm{M}+\mathrm{H}]^{+} 407.2335$, found 407.2343.

\subsubsection{General procedure for the synthesis of 3-aryl-1-(phenylsulfonyl)indoles}

6a-6c-The method adopted for the synthesis of 3-phenyl-1-(phenylsulfonyl)indole (6a) is described. To a solution of phenylboronic acid $(0.49 \mathrm{~g}, 4.1 \mathrm{mmol})$ in benzene $(21 \mathrm{~mL})$ and ethanol $(10 \mathrm{~mL})$ were added potassium carbonate $(0.680 \mathrm{~g}, 4.4 \mathrm{mmol})$ and 3-bromo-1(phenylsulfonyl)indole (5) $(1.2 \mathrm{~g}, 3.4 \mathrm{mmol})$. The reaction mixture was stirred at room temperature and deoxygenated by passing through it a steam of argon for $15 \mathrm{~min}$. Palladium triphenylphosphine tetrakis $(0.039 \mathrm{mg}, 0.034 \mathrm{mmol})$ was added and the solution was refluxed for $16 \mathrm{~h}$. After cooling, the mixture was poured into $25 \mathrm{~mL}$ of water, extracted with ethyl acetate $(3 \times 30 \mathrm{~mL})$, washed with saturated aqueous $\mathrm{NaCl}$ and dried. The solvent was removed in vacuo, and the residue was chromatographed on a silica gel column using hexane/ethyl acetate (9:1) to give $0.955 \mathrm{~g}(84 \%)$ of 3-phenyl-1-(phenylsulfonyl)indole as a white solid. mp $144-146{ }^{\circ} \mathrm{C} .{ }^{1} \mathrm{H} \mathrm{NMR}\left(400 \mathrm{MHz}, \mathrm{CDCl}_{3}\right) \delta 8.10(\mathrm{~d}, J=8.2 \mathrm{~Hz}, 1 \mathrm{H}), 7.95$ $(\mathrm{d}, J=7.3 \mathrm{~Hz}, 2 \mathrm{H}), 7.81(\mathrm{~d}, J=7.9 \mathrm{~Hz}, 1 \mathrm{H}), 7.73(\mathrm{~s}, 1 \mathrm{H}), 7.63(\mathrm{~d}, J=7.4 \mathrm{~Hz}, 2 \mathrm{H})$, 7.57-7.27 (m, 8H). ${ }^{13} \mathrm{C}$ NMR (100 MHz, DMSO- $\left.d_{6}\right) \delta 137.07,135.34,134.00,130.37$, 
$129.52,127.30,126.59,126.08,124.79,120.13,113.85,99.44$. MS (APCI) $m / z 334.9$ [M $+\mathrm{H}]^{+}$.

4.1.10. 3-(4-Fluorophenyl)-1-(phenylsulfonyl)indole (6b)-This compound was prepared from 3-bromo-1-(phenylsulfonyl)indole (5) and 4-fluorophenylboronic acid as described for 6a. $91 \%$ yield, white solid. ${ }^{1} \mathrm{H}$ NMR $\left(400 \mathrm{MHz}, \mathrm{CDCl}_{3}\right): \delta 8.07(\mathrm{~d}, J=8.3 \mathrm{~Hz}$, $1 \mathrm{H}), 7.92(\mathrm{~d}, J=7.5 \mathrm{~Hz}, 2 \mathrm{H}), 7.70(\mathrm{~d}, J=7.9 \mathrm{~Hz}, 1 \mathrm{H}), 7.65(\mathrm{~s}, 1 \mathrm{H}), 7.55-7.50(\mathrm{~m}, 3 \mathrm{H}), 7.43$ $(\mathrm{t}, J=7.9 \mathrm{~Hz}, 2 \mathrm{H}), 7.36(\mathrm{t}, J=7.4 \mathrm{~Hz}, 1 \mathrm{H}), 7.28(\mathrm{t}, J=7.4 \mathrm{~Hz}, 1 \mathrm{H}), 7.14(\mathrm{t}, J=8.6 \mathrm{~Hz}$, $2 \mathrm{H}),{ }^{13} \mathrm{C} \mathrm{NMR}\left(100 \mathrm{MHz}, \mathrm{CDCl}_{3}\right): \delta 162.56(\mathrm{~d}, J=245.5 \mathrm{~Hz}), 138.38,135.67,134.11$, $129.73(\mathrm{~d}, J=7.9 \mathrm{~Hz}), 129.54,129.45,129.20(\mathrm{~d}, J=3.3 \mathrm{~Hz}), 127.03,125.29,123.92$, $123.40,122.99,120.43,116.09(\mathrm{~d}, J=21.4 \mathrm{~Hz}), 114.07$. MS (EI) $\mathrm{m} / z .374[\mathrm{M}+\mathrm{Na}]^{+}$.

4.1.11. 3-(Furan-3-yl)-1-(phenylsulfonyl)-1 $\boldsymbol{H}$-indole (6c)-This compound was prepared from 3-bromo-1-(phenylsulfonyl)indole (5) and furan-3-boronic acid as described for 6a. 97\% yield, yellow solid. mp $88-91{ }^{\circ} \mathrm{C} .{ }^{1} \mathrm{H}$ NMR $\left(400 \mathrm{MHz}, \mathrm{CDCl}_{3}\right) \delta 8.08(\mathrm{~d}, J=$ $8.3 \mathrm{~Hz}, 1 \mathrm{H}), 8.03-7.88(\mathrm{~m}, 2 \mathrm{H}), 7.83(\mathrm{~s}, 1 \mathrm{H}), 7.78-7.63(\mathrm{~m}, 2 \mathrm{H}), 7.56-7.49(\mathrm{~m}, 2 \mathrm{H})$, $7.47-7.35(\mathrm{~m}, 3 \mathrm{H}), 7.33-7.27(\mathrm{~m}, 1 \mathrm{H}), 6.71(\mathrm{~s}, 1 \mathrm{H}) .{ }^{13} \mathrm{C} \mathrm{NMR}\left(100 \mathrm{MHz}, \mathrm{CDCl}_{3}\right) \delta$ $143.45,139.07,138.10,135.46,133.90,129.32,129.14,126.79,125.13,123.70,122.44$, $120.48,117.67,115.41,113.85,109.66$. MS (APCI) $m / z 323.9[\mathrm{M}]^{+}$.

4.1.12. General procedure for the synthesis of 3-arylindoles $7 a-7 c-T h e$ method adopted for the synthesis of 3-phenylindole (7a) is described. $\mathrm{Mg}(2.12 \mathrm{~g}, 875 \mathrm{mmol})$ and ammonium chloride $(0.04 \mathrm{~g}, 0.8 \mathrm{mmol})$ were added to a stirred solution of $6 \mathbf{6}(0.85 \mathrm{~g}, 2.5$ $\mathrm{mmol})$ in methanol $(80 \mathrm{~mL})$ and THF $(20 \mathrm{~mL})$. The exothermic mixture was stirred for $2 \mathrm{~h}$ at room temperature and was concentrated under reduced pressure. A saturated solution of ammonium chloride $(30 \mathrm{~mL})$ was then added and the mixture was extracted with ethyl acetate $(3 * 100 \mathrm{~mL})$. The organic layer was washed with water and brine, dried and evaporated. The residue was chromatographed on a silica gel column using hexane/ethyl acetate (8:2) to give $0.28 \mathrm{~g}(60 \%)$ of 3 -phenyl- $1 H$-indole as a white solid. ${ }^{1} \mathrm{H}$ NMR (400 $\left.\mathrm{MHz}, \mathrm{CDCl}_{3}\right) \delta 8.14(\mathrm{~d}, J=7.4 \mathrm{~Hz}, 1 \mathrm{H}), 7.96(\mathrm{~s}, 1 \mathrm{H}), 7.83(\mathrm{~d}, J=7.1 \mathrm{~Hz}, 2 \mathrm{H}), 7.61(\mathrm{t}, J=$ $7.7 \mathrm{~Hz}, 2 \mathrm{H}), 7.55-7.34(\mathrm{~m}, 3 \mathrm{H}), 7.31(\mathrm{~d}, J=2.5 \mathrm{~Hz}, 1 \mathrm{H}) .{ }^{13} \mathrm{C} \mathrm{NMR}\left(100 \mathrm{MHz}, \mathrm{CDCl}_{3}\right) \delta$ $136.77,135.74,129.02,127.62,126.19,125.80,122.55,122.12,120.51,119.94,118.20$, 111.69. MS (APCI) $\mathrm{m} / z 193.1[\mathrm{M}]^{+}$.

4.1.13. 3-(4-Fluorophenyl)indole (7b)-This compound was prepared from $6 \mathbf{b}$ as described for 7a. $80 \%$ yield, white solid. mp $105-107{ }^{\circ} \mathrm{C} .{ }^{1} \mathrm{H}$ NMR (400 MHz, DMSO- $\left.d_{6}\right)$ : $\delta 11.40(\mathrm{~s}, 1 \mathrm{H}), 7.85(\mathrm{~d}, J=7.6 \mathrm{~Hz}, 1 \mathrm{H}), 7.73-7.67(\mathrm{~m}, 3 \mathrm{H}), 7.51(\mathrm{~d}, J=8.0 \mathrm{~Hz}, 1 \mathrm{H}), 7.25$ $(\mathrm{t}, J=8.8 \mathrm{~Hz}, 2 \mathrm{H}), 7.19(\mathrm{t}, J=7.2 \mathrm{~Hz}, 2 \mathrm{H}), 7.12(\mathrm{t}, J=7.2 \mathrm{~Hz}, 2 \mathrm{H}) .{ }^{13} \mathrm{C}$ NMR $(100 \mathrm{MHz}$, DMSO- $\left.d_{6}\right): \delta 161.47,159.07,136.78,132.21,128.09,128.01,124.84,123.22,121.37$, $119.54,118.70,115.47,115.26,114.67,111.88$. MS (ESI) $\mathrm{m} / 2.210[\mathrm{M}-\mathrm{H}]^{+}$.

4.1.14. 3-(Furan-3-yl)indole (7c)-This compound was prepared from $\mathbf{6 c}$ as described for 7a. 89\% yield, yellow solid. ${ }^{1} \mathrm{H}$ NMR $\left(400 \mathrm{MHz}, \mathrm{CDCl}_{3}\right) \delta 8.06(\mathrm{~s}, 1 \mathrm{H}), 7.98-7.81(\mathrm{~m}$, 2H), $7.60(\mathrm{~s}, 1 \mathrm{H}), 7.40(\mathrm{~d}, J=7.7 \mathrm{~Hz}, 1 \mathrm{H}), 7.37-7.21(\mathrm{~m}, 2 \mathrm{H}), 6.78(\mathrm{~s}, 1 \mathrm{H}) .{ }^{13} \mathrm{C}$ NMR $(100$ $\left.\mathrm{MHz}, \mathrm{CDCl}_{3}\right) \delta 143.06,137.74,136.57,125.74,122.55,121.57,120.30,119.88,119.72$, 111.52, 109.92, 109.06. MS (APCI) $\mathrm{m} / z 184.0[\mathrm{M}]^{+}$.

4.1.15. 1-(4-Bromobutyl)-3-phenylindole (8a)-This compound was prepared from 3phenylindole (7a) as described for 3a. 77\% yield, colorless oil. ${ }^{1} \mathrm{H}$ NMR $\left(400 \mathrm{MHz}, \mathrm{CDCl}_{3}\right)$ $\delta 8.05-8.03(\mathrm{~m}, 1 \mathrm{H}), 7.74(\mathrm{~d}, J=7.0 \mathrm{~Hz}, 2 \mathrm{H}), 7.52(\mathrm{t}, J=7.7 \mathrm{~Hz}, 2 \mathrm{H}), 7.43(\mathrm{~d}, J=8.2 \mathrm{~Hz}$, $1 \mathrm{H}), 7.40-7.22(\mathrm{~m}, 4 \mathrm{H}), 4.32-4.11(\mathrm{~m}, 2 \mathrm{H}), 3.48-3.33(\mathrm{~m}, 2 \mathrm{H}), 2.18-2.00(\mathrm{~m}, 2 \mathrm{H}), 1.95-1.88$ (m, 2H). ${ }^{13} \mathrm{C}$ NMR $\left(100 \mathrm{MHz}, \mathrm{CDCl}_{3}\right) \delta 136.80,135.62,128.85,127.40,126.38,125.88$, 
125.39, 122.11, 120.18, 120.08, 117.09, 109.68, 45.57, 33.05, 30.0, 28.85. MS (APCI) $\mathrm{m} / \mathrm{z}$ $327[\mathrm{M}]^{+}$for ${ }^{79} \mathrm{Br}, 329[\mathrm{M}]^{+}$for ${ }^{81} \mathrm{Br}$.

4.1.16. 1-(4-Bromobutyl)-3-(4-fluorophenyl)indole (8b)-This compound was prepared from $\mathbf{7 b}$ as described for 3a. $83 \%$ yield, colorless oil. ${ }^{1} \mathrm{H}$ NMR $\left(400 \mathrm{MHz}, \mathrm{CDCl}_{3}\right)$ : $\delta 7.86(\mathrm{~d}, J=7.9 \mathrm{~Hz}, 1 \mathrm{H}), 7.60-7.56(\mathrm{~m}, 2 \mathrm{H}), 7.37(\mathrm{~d}, J=8.2 \mathrm{~Hz}, 1 \mathrm{H}), 7.26(\mathrm{t}, J=7.7 \mathrm{~Hz}$, $1 \mathrm{H}), 7.20-7.16(\mathrm{~m}, 2 \mathrm{H}), 7.12(\mathrm{t}, J=8.7 \mathrm{~Hz}, 2 \mathrm{H}), 4.18(\mathrm{t}, J=6.8 \mathrm{~Hz}, 2 \mathrm{H}), 3.38(\mathrm{t}, J=6.5 \mathrm{~Hz}$, 2H), 2.08-2.01 (m, 2H), 1.92-1.85 (m, 2H). $\left.{ }^{13} \mathrm{C} \mathrm{NMR} \mathrm{(100} \mathrm{MHz,} \mathrm{CDCl}_{3}\right): \delta 161.60(\mathrm{~d}, J=$ $243.0 \mathrm{~Hz}$ ), 136.87, 131.75 (d, $J=3.3 \mathrm{~Hz}), 128.99$ (d, $J=7.6 \mathrm{~Hz}), 126.50,125.28,122.35$, $120.27,120.03,116.41,115.79(\mathrm{~d}, J=21.1 \mathrm{~Hz}), 109.82,45.77,33.08,30.19,29.03$. MS (ESI) $\mathrm{m} / \mathrm{z}, 346[\mathrm{M}+\mathrm{H}]^{+}$for ${ }^{79} \mathrm{Br}, 348[\mathrm{M}+\mathrm{H}]^{+}$for ${ }^{81} \mathrm{Br}$.

4.1.17. 1-(4-Bromobutyl)-3-furan-3-ylindole (8c)-This compound was prepared from 7c as described for 3a. $75 \%$ yield, yellow oil. ${ }^{1} \mathrm{H}$ NMR $\left(400 \mathrm{MHz}, \mathrm{CDCl}_{3}\right) \delta$ 7.89-7.76 (m, $2 \mathrm{H}), 7.54(\mathrm{t}, J=1.6 \mathrm{~Hz}, 1 \mathrm{H}), 7.37(\mathrm{~d}, J=8.1 \mathrm{~Hz}, 1 \mathrm{H}), 7.34-7.26(\mathrm{~m}, 1 \mathrm{H}), 7.25-7.15(\mathrm{~m}$, $2 \mathrm{H}), 6.80-6.64(\mathrm{~m}, 1 \mathrm{H}), 4.15-4.09(\mathrm{~m}, 2 \mathrm{H}), 3.45(\mathrm{t}, J=6.5 \mathrm{~Hz}, 2 \mathrm{H}), 2.06-2.00(\mathrm{~m}, 2 \mathrm{H})$, $1.91-1.78(\mathrm{~m}, 3 \mathrm{H}) .{ }^{13} \mathrm{C} \mathrm{NMR}\left(100 \mathrm{MHz}, \mathrm{CDCl}_{3}\right) \delta 142.96,137.49,136.62,126.30,124.88$, $122.11,120.13,119.85,119.62,109.79,109.59,107.87,45.47,33.03,29.96,28.84$. MS (APCI) $m / z 327[\mathrm{M}]^{+}$for ${ }^{79} \mathrm{Br}, 329[\mathrm{M}]^{+}$for ${ }^{81} \mathrm{Br}$.

4.1.18. 1-[4-(4-Cyclohexyl-piperazin-1-yl)-butyl]-3-phenylindole dioxalate (9a)This compound was prepared from 8a and 1-cyclohexylpiperazine as described for $\mathbf{4 a}$. $21 \%$ yield, white solid. mp $242-244{ }^{\circ} \mathrm{C} .{ }^{1} \mathrm{H}$ NMR (free amine, $\left.400 \mathrm{MHz}, \mathrm{CDCl}_{3}\right) \delta 7.96(\mathrm{~d}, J=$ $8.0 \mathrm{~Hz}, 1 \mathrm{H}), 7.67(\mathrm{~d}, J=7.3 \mathrm{~Hz}, 2 \mathrm{H}), 7.45(\mathrm{t}, J=7.7 \mathrm{~Hz}, 2 \mathrm{H}), 7.39$ (d, $J=8.2 \mathrm{~Hz}, 1 \mathrm{H})$, 7.32-7.23 (m, 3H), $7.19(\mathrm{t}, J=7.4 \mathrm{~Hz}, 1 \mathrm{H}), 4.18(\mathrm{t}, J=7.0 \mathrm{~Hz}, 2 \mathrm{H}), 2.70(\mathrm{~s}, 4 \mathrm{H}), 2.55(\mathrm{~s}$, $4 \mathrm{H}), 2.47-2.30(\mathrm{~m}, 2 \mathrm{H}), 2.03-1.86(\mathrm{~m}, 4 \mathrm{H}), 1.81(\mathrm{~s}, 2 \mathrm{H}), 1.75-1.63(\mathrm{~m}, 1 \mathrm{H}), 1.60-1.55(\mathrm{~m}$, 2H), 1.37-1.17 (m, 5H), 1.12 (s, 1H). ${ }^{13} \mathrm{C}$ NMR (free amine, $100 \mathrm{MHz}, \mathrm{CDCl}_{3}$ ) $\delta 136.74$, 135.66, 128.76, 127.29, 126.26, 125.71, 125.51, 121.86, 120.04, 119.86, 116.74, 109.73, $63.99,57.62,52.52,48.60,46.26,28.35,28.01,25.97,25.66,24.13$. HRMS (TOF ES+) calcd for $\mathrm{C}_{28} \mathrm{H}_{38} \mathrm{~N}_{3}[\mathrm{M}+\mathrm{H}]^{+} 416.3066$, found 416.3081 .

\subsubsection{1-\{4-[4-(4-Fluorophenyl)-piperazin-1-yl]-butyl\}-3-phenylindole oxalate} (9b)-This compound was prepared from 8a and 1-(4-fluorophenyl)piperazine as described for 4a. $28 \%$ yield, white solid. mp $195-197{ }^{\circ} \mathrm{C} .{ }^{1} \mathrm{H}$ NMR (free amine, $400 \mathrm{MHz}, \mathrm{CDCl}_{3}$ ) $\delta$ $8.00(\mathrm{~d}, J=7.9 \mathrm{~Hz}, 1 \mathrm{H}), 7.71(\mathrm{~d}, J=7.5 \mathrm{~Hz}, 2 \mathrm{H}), 7.55-7.38(\mathrm{~m}, 3 \mathrm{H}), 7.31(\mathrm{~d}, J=5.6 \mathrm{~Hz}$, $3 \mathrm{H}), 7.23(\mathrm{~d}, J=7.4 \mathrm{~Hz}, 1 \mathrm{H}), 6.98(\mathrm{t}, J=8.5 \mathrm{~Hz}, 2 \mathrm{H}), 6.88(\mathrm{~s}, 2 \mathrm{H}), 4.21(\mathrm{t}, J=6.9 \mathrm{~Hz}, 2 \mathrm{H})$, $3.12(\mathrm{~s}, 4 \mathrm{H}), 2.58(\mathrm{~s}, 4 \mathrm{H}), 2.52-2.36(\mathrm{~m}, 2 \mathrm{H}), 1.97(\mathrm{~m}, 2 \mathrm{H}), 1.62(\mathrm{~m}, 2 \mathrm{H}) .{ }^{13} \mathrm{C}$ NMR (free amine, $\left.100 \mathrm{MHz}, \mathrm{CDCl}_{3}\right) \delta 158.39,156.02,147.94,136.82,135.71,128.78,127.33,126.33$, $125.62(\mathrm{~d}, J=23.6 \mathrm{~Hz}), 121.99,120.00(\mathrm{~d}, J=17.7 \mathrm{~Hz}), 117.83(\mathrm{~d}, J=7.6 \mathrm{~Hz}), 115.50(\mathrm{~d}, J$ $=22.0 \mathrm{~Hz}$ ), 109.73, 77.40, 77.08, 76.76, 57.82, 53.16, 50.03, 46.29, 28.07, 24.18. Anal. calc. for $\mathrm{C}_{30} \mathrm{H}_{32} \mathrm{FN}_{3} \mathrm{O}_{4} \cdot 1 / 3 \mathrm{H}_{2} \mathrm{O}: \mathrm{C}, 68.82 ; \mathrm{H}, 6.29 ; \mathrm{N}, 8.03$. Found: $\mathrm{C}, 68.95 ; \mathrm{H}, 6.03 ; \mathrm{N}, 8.01$. HRMS (TOF ES+) calcd for $\mathrm{C}_{28} \mathrm{H}_{31} \mathrm{~N}_{3} \mathrm{~F}[\mathrm{M}+\mathrm{H}]^{+} 428.2502$, found 428.2516 .

\subsubsection{6,7-Dimethoxy-2-(4-(3-phenylindol-1-yl)butyl)-1,2,3,4-} tetrahydroisoquinoline oxalate (9c) - This compound was prepared from 8a and 6,7dimethoxy-1,2,3,4-tetrahydroisoquinoline as described for $\mathbf{4 a}$. 30\% yield, white solid. $\mathrm{mp}$ $189-190{ }^{\circ} \mathrm{C} .{ }^{1} \mathrm{H}$ NMR (free amine, $\left.400 \mathrm{MHz}, \mathrm{CDCl} 3\right) \delta 7.98-7.96(\mathrm{~m}, 2 \mathrm{H}), 7.68(\mathrm{~d}, J=$ $7.2 \mathrm{~Hz}, 2 \mathrm{H}), 7.53-7.36(\mathrm{~m}, 3 \mathrm{H}), 7.31(\mathrm{~s}, 1 \mathrm{H}), 7.29-7.24(\mathrm{~m}, 2 \mathrm{H}), 7.19(\mathrm{t}, J=7.3 \mathrm{~Hz}, 1 \mathrm{H})$, $6.59(\mathrm{~s}, 1 \mathrm{H}), 6.49(\mathrm{~s}, 1 \mathrm{H}), 4.22-4.19(\mathrm{~m}, 2 \mathrm{H}), 3.83(\mathrm{~m}, 6 \mathrm{H}), 3.51(\mathrm{~s}, 2 \mathrm{H}), 2.81-2.79(\mathrm{~m}, 2 \mathrm{H})$, 2.70-2.68 (m, 2H), 2.53-2.50 (m, 2H), 1.97-1.95 (m, 2H), 1.66-1.64 (m, 2H). ${ }^{13} \mathrm{C}$ NMR (free amine, $\left.100 \mathrm{MHz}, \mathrm{CDCl}_{3}\right) \delta 162.56,147.59,147.28,136.83,136.83,135.73,135.73,128.74$, $127.28,126.32(\mathrm{~d}, J=6.9 \mathrm{~Hz}), 126.09,125.67,125.56,121.86,119.93(\mathrm{~d}, J=14.3 \mathrm{~Hz})$, 
$116.71,111.46,109.68$ (d, $J=19.9 \mathrm{~Hz}), 57.51,55.93,55.57,50.94,46.27,36.42,28.48$, 28.10, 24.49. Anal. calc. for $\mathrm{C}_{31} \mathrm{H}_{34} \mathrm{~N}_{2} \mathrm{O}_{6} \cdot 1 / 2 \mathrm{H}_{2} \mathrm{O}: \mathrm{C}, 69.00 ; \mathrm{H}, 6.54 ; \mathrm{N}, 5.19$. Found: $\mathrm{C}$, 68.60; H, 6.11; N, 5.12. HRMS (TOF ES+) calcd for $\mathrm{C}_{29} \mathrm{H}_{33} \mathrm{~N}_{2} \mathrm{O}_{2}[\mathrm{M}+\mathrm{H}]^{+} 441.2542$, found 441.2521 .

\subsubsection{1-(4-(4-Cyclohexylpiperazin-1-yl)butyl)-3-(4-fluorophenyl)indole dioxalate (9d)-This compound was prepared from $\mathbf{8 b}$ and 1-cyclohexylpiperazine as described for 4a. $28 \%$ yield, white solid. mp $248-249{ }^{\circ} \mathrm{C} .{ }^{1} \mathrm{H}$ NMR (400 MHz, DMSO- $\left.d_{6}\right)$ : $\delta 10.98$ (br s, 4H), 7.81 (d, $J=7.6 \mathrm{~Hz}, 1 \mathrm{H}), 7.70-7.65(\mathrm{~m}, 3 \mathrm{H}), 7.53(\mathrm{~d}, J=7.8 \mathrm{~Hz}, 1 \mathrm{H})$, 7.26-7.09 (m, 4H), 4.20 (s, 2H), 2.98-2.47 (m, 11H), 1.88-1.75 (m, 6H), 1.56-1.47 (m, 3H), 1.23-1.04 (m, 5H). ${ }^{13} \mathrm{C}$ NMR (125 MHz, DMSO- $\left.d_{6}\right): \delta 164.73,163.36$, (d, $\left.J=241.0 \mathrm{~Hz}\right)$, $136.53,131.91,128.18$ (d, $J=7.6 \mathrm{~Hz}), 126.72,125.28,121.61,119.86,119.18,115.64(\mathrm{~d}, J$ $=20.8 \mathrm{~Hz}$ ), 114.01, 110.44, 63.11, 56.27, 51.13, 47.54, 45.33, 27.33, 26.32, 25.30, 24.89, 22.86. Anal. calcd for $\mathrm{C}_{32} \mathrm{H}_{40} \mathrm{FN}_{3} \mathrm{O}_{8}$ : C, 62.63; H, 6.57; N, 6.85. Found: C, 62.48; H, 6.25; $\mathrm{N}$, 6.76. HRMS (TOF ES+) calcd for $\mathrm{C}_{28} \mathrm{H}_{37} \mathrm{~N}_{3} \mathrm{~F}[\mathrm{M}+\mathrm{H}]^{+} 434.2972$, found 434.2987.}

\subsubsection{3-(4-Fluorophenyl)-1-(4-(4-(4-fluorophenyl)piperazin-1-yl)butyl)indole oxalate (9e)-This compound was prepared from $\mathbf{8 b}$ and 1-(4-fluorophenyl)piperazine as described for 4a. $54 \%$ yield, white solid. mp $214-216{ }^{\circ} \mathrm{C} .{ }^{1} \mathrm{H}$ NMR (500 MHz, DMSO- $\left.d_{6}\right)$ : $\delta 11.40$ (br s, $2 \mathrm{H}), 7.84(\mathrm{~d}, J=7.9 \mathrm{~Hz}, 1 \mathrm{H}), 7.76(\mathrm{~s}, 1 \mathrm{H}), 7.70-7.67(\mathrm{~m}, 2 \mathrm{H}), 7.58(\mathrm{~d}, J=8.2$ $\mathrm{Hz}, 1 \mathrm{H}), 7.26(\mathrm{t}, J=8.6 \mathrm{~Hz}, 2 \mathrm{H}), 7.22(\mathrm{t}, J=7.6 \mathrm{~Hz}, 1 \mathrm{H}), 7.13(\mathrm{t}, J=7.5 \mathrm{~Hz}, 1 \mathrm{H}), 7.07(\mathrm{t}, J$ $=8.7 \mathrm{~Hz}, 2 \mathrm{H}), 6.99-6.96(\mathrm{~m}, 2 \mathrm{H}), 4.25(\mathrm{t}, J=6.7 \mathrm{~Hz}, 2 \mathrm{H}), 3.26(\mathrm{br} \mathrm{s}, 4 \mathrm{H}), 3.10(\mathrm{br} \mathrm{s}, 4 \mathrm{H})$, 2.97 (br s, 2H), 1.85-1.83 (m, 2H), 1.66 (br s, 2H). $\left.{ }^{13} \mathrm{C} \mathrm{NMR} \mathrm{(125,} \mathrm{MHz,} \mathrm{DMSO-} d_{6}\right): \delta$ 164.05, $160.38(\mathrm{~d}, J=240.4 \mathrm{~Hz}), 156.43(\mathrm{~d}, J=235.1 \mathrm{~Hz}), 146.76,136.44,131.86(\mathrm{~d}, J=$ $3.0 \mathrm{~Hz}), 128.18$ (d, $J=7.7 \mathrm{~Hz}), 126.70,125.29,121.63,119.88,119.16,117.62$ (d, J = 7.7 $\mathrm{Hz}), 115.61(\mathrm{~d}, J=21.0 \mathrm{~Hz}), 115.43(\mathrm{~d}, J=21.8 \mathrm{~Hz}), 114.08,110.37,55.31,51.01$, 46.72, 45.07, 27.04, 21.29. Anal. calcd for $\mathrm{C}_{30} \mathrm{H}_{31} \mathrm{~F}_{2} \mathrm{~N}_{3} \mathrm{O}_{4}$ : C, 67.28; H, 5.83; N, 7.85. Found: C, 67.08; H, 5.80; N, 7.73. HRMS (TOF ES+) calcd for $\mathrm{C}_{28} \mathrm{H}_{30} \mathrm{~N}_{3} \mathrm{~F}_{2}[\mathrm{M}+\mathrm{H}]^{+} 446.2408$, found 446.2391.}

\subsubsection{2-(4-(3-(4-Fluorophenyl)indol-1-yl)butyl)-6,7-dimethoxy-1,2,3,4- tetrahydroisoquinoline oxalate (9f)-This compound was prepared from $\mathbf{8 b}$ and 6,7-

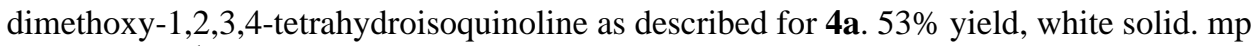 182-184 ${ }^{\circ} \mathrm{C}$. ${ }^{1} \mathrm{H}$ NMR (500 MHz, DMSO- $\left.d_{6}\right): \delta 10.52$ (br s, $\left.2 \mathrm{H}\right), 7.84(\mathrm{~d}, J=8.0 \mathrm{~Hz}, 1 \mathrm{H})$, $7.75(\mathrm{~s}, 1 \mathrm{H}), 7.70-7.67(\mathrm{~m}, 2 \mathrm{H}), 7.58(\mathrm{~d}, J=8.2 \mathrm{~Hz}, 1 \mathrm{H}), 7.26(\mathrm{t}, J=8.8 \mathrm{~Hz}, 2 \mathrm{H}), 7.22(\mathrm{t}, J$ $=7.6 \mathrm{~Hz}, 1 \mathrm{H}), 7.13(\mathrm{t}, J=7.4 \mathrm{~Hz}, 1 \mathrm{H}), 6.77(\mathrm{~s}, 1 \mathrm{H}), 6.72(\mathrm{~s}, 1 \mathrm{H}), 4.26(\mathrm{t}, J=6.8 \mathrm{~Hz}, 2 \mathrm{H})$, 4.15 (br s, 2H), 3.72 (s, 3H), 3.70 (s, 3H), 3.32 (br s, 2H), 3.13-3.09 (m, 2H), 2.92 (br s, 2H), 1.90-1.85 (m, 2H), 1.75 (br s, 2H). ${ }^{13} \mathrm{C}$ NMR (125 MHz, DMSO-d 6 ): $\delta 164.34,160.39$ (d, $J$ $=240.4 \mathrm{~Hz}), 148.15,147.55,136.45,131.85,128.20$ (d, $J=7.7 \mathrm{~Hz}), 126.69,125.32,123.50$, 121.64, 120.61, 119.90, 119.17, 115.61 (d, $J=21.0 \mathrm{~Hz}), 114.11,111.46,110.40,109.67$, 55.53, 55.48, 54.51, 51.70, 48.90, 45.05, 26.92, 24.68, 21.29. HRMS (TOF ES+) calcd for $\mathrm{C}_{29} \mathrm{H}_{32} \mathrm{~N}_{2} \mathrm{O}_{2} \mathrm{~F}[\mathrm{M}+\mathrm{H}]^{+} 459.2448$, found 459.2456 .}

\subsubsection{1-[4-(4-Cyclohexyl-piperazin-1-yl)-butyl]-3-furan-3-ylindole dioxalate}

$(\mathbf{g g}$ - - This compound was prepared from $\mathbf{8 c}$ and 1-cyclohexylpiperazine as described for 4a. $21 \%$ yield, white solid. mp 240-243 ${ }^{\circ} \mathrm{C}$. ${ }^{1} \mathrm{H}$ NMR (free amine, $400 \mathrm{MHz}, \mathrm{CDCl}_{3}$ ) $\delta$ 7.85-7.69 (m, 2H), 7.49 (s, 1H), 7.34 (d, J=8.1 Hz, 1H), 7.27-7.20 (m, 2H), 7.16 (t, J= 7.4 $\mathrm{Hz}, 1 \mathrm{H}), 6.69(\mathrm{~s}, 1 \mathrm{H}), 4.11(\mathrm{t}, J=6.8 \mathrm{~Hz}, 2 \mathrm{H}), 2.72(\mathrm{~s}, 4 \mathrm{H}), 2.54(\mathrm{~s}, 4 \mathrm{H}), 2.45(\mathrm{~s}, 1 \mathrm{H})$, 2.40-2.27 (m, 2H), $1.94(\mathrm{~s}, 2 \mathrm{H}), 1.87-1.81(\mathrm{~m}, 4 \mathrm{H}), 1.61(\mathrm{~m}, 2 \mathrm{H}), 1.55-1.48(\mathrm{~m}, 2 \mathrm{H})$, 1.28-1.22 (m, 3H), 1.15-1.08 (s, 1H). ${ }^{13} \mathrm{C} \mathrm{NMR} \mathrm{(free} \mathrm{amine,} 100 \mathrm{MHz}, \mathrm{CDCl}_{3}$ ) $\delta 142.90$, $137.34,136.57,126.20,125.09,121.91,120.03,119.69,119.67,109.74,109.69,107.53$, $64.17,57.43,52.06,48.47,46.14,28.10,27.92,25.81,25.54,23.98$. Anal. calc. for 
$\mathrm{C}_{30} \mathrm{H}_{39} \mathrm{~N}_{3} \mathrm{O}_{9} \cdot 1 / 2 \mathrm{H}_{2} \mathrm{O}: \mathrm{C}, 60.59 ; \mathrm{H}, 6.79 ; \mathrm{N}, 7.07$. Found: $\mathrm{C}, 60.20 ; \mathrm{H}, 6.39 ; \mathrm{N}, 7.01$. HRMS

(TOF ES+) calcd for $\mathrm{C}_{26} \mathrm{H}_{36} \mathrm{~N}_{3} \mathrm{O}[\mathrm{M}+\mathrm{H}]^{+} 406.2858$, found 406.2874 .

4.1.25. 1-\{4-[4-(4-Fluorophenyl)-piperazin-1-yl]-butyl\}-3-furan-3-ylindole dioxalate (9h)-This compound was prepared from $8 \mathbf{c}$ and 1-(4-fluorophenyl)piperazine as described for 4a. $46 \%$ yield, white solid. mp $172-174{ }^{\circ} \mathrm{C}$. ${ }^{1} \mathrm{H}$ NMR (free amine, 400 $\left.\mathrm{MHz}, \mathrm{CDCl}_{3}\right) \delta$ 7.93-7.75 (m, 2H), 7.55-7.54 (m, $\left.1 \mathrm{H}\right), 7.41(\mathrm{~d}, J=8.2 \mathrm{~Hz}, 1 \mathrm{H}), 7.31-7.20$ $(\mathrm{m}, 3 \mathrm{H}), 7.01-6.96(\mathrm{~m}, 2 \mathrm{H}), 6.89-6.86(\mathrm{~m}, 2 \mathrm{H}), 6.73(\mathrm{~s}, 1 \mathrm{H}), 4.18(\mathrm{t}, J=7.0 \mathrm{~Hz}, 2 \mathrm{H}), 3.11(\mathrm{t}$, $J=4 \mathrm{~Hz}, 4 \mathrm{H}), 2.56(\mathrm{t}, J=4 \mathrm{~Hz}, 4 \mathrm{H}), 2.44-2.40$ (m, 2H), 2.03-1.85 (m, 2H), 1.63-1.59 (m, $2 \mathrm{H}) .{ }^{13} \mathrm{C}$ NMR (free amine, $\left.100 \mathrm{MHz}, \mathrm{CDCl}_{3}\right) \delta 158.35,154.92(\mathrm{~d}, J=212.2 \mathrm{~Hz}), 147.98$ (d, $J=2.2 \mathrm{~Hz}), 142.94,137.45,136.64,126.29,125.06,121.96,119.92(\mathrm{~d}, J=36.5 \mathrm{~Hz})$, 117.78 (d, $J=7.6 \mathrm{~Hz}$ ), 115.62, 115.40, 109.81, 109.70, 107.62, 57.90, 53.22, 50.11, 46.26, 28.14, 24.28. Anal. calc. for $\mathrm{C}_{30} \mathrm{H}_{32} \mathrm{FN}_{3} \mathrm{O}_{9} .1 / 2 \mathrm{H}_{2} \mathrm{O}: \mathrm{C}, 59.40 ; \mathrm{H}, 5.48 ; \mathrm{N}, 6.93$. Found: $\mathrm{C}$, 59.47; H, 5.15; N, 6.92. HRMS (TOF ES+) calcd for $\mathrm{C}_{26} \mathrm{H}_{29} \mathrm{~N}_{3} \mathrm{OF}[\mathrm{M}+\mathrm{H}]^{+} 418.2295$, found 418.2298 .

4.1.26. 2-(4-(3-(Furan-3-yl)indol-1-yl)butyl)-6,7-dimethoxy-1,2,3,4tetrahydroisoquinoline oxalate (9i)-This compound was prepared from $8 \mathbf{c}$ and $6,7-$ dimethoxy-1,2,3,4-tetrahydroisoquinoline as described for $\mathbf{4 a} .42 \%$ yield, white solid. $\mathrm{mp}$ $156{ }^{\circ} \mathrm{C} .{ }^{1} \mathrm{H}$ NMR (free amine, $\left.400 \mathrm{MHz}, \mathrm{CDCl}_{3}\right) \delta$ 7.90-7.78 (m, 2H), $7.52(\mathrm{~s}, 1 \mathrm{H}), 7.40(\mathrm{~d}$, $J=8.1 \mathrm{~Hz}, 1 \mathrm{H}), 7.30-7.24(\mathrm{~m}, 2 \mathrm{H}), 7.21(\mathrm{t}, J=7.4 \mathrm{~Hz}, 1 \mathrm{H}), 6.72(\mathrm{~s}, 1 \mathrm{H}), 6.61(\mathrm{~s}, 1 \mathrm{H}), 6.51$ (s, $1 \mathrm{H}), 4.18(\mathrm{t}, J=6.9 \mathrm{~Hz}, 3 \mathrm{H}), 3.86-6.84(\mathrm{~m}, 6 \mathrm{H}), 3.52(\mathrm{~s}, 2 \mathrm{H}), 2.84-2.80(\mathrm{~m}, 2 \mathrm{H}), 2.69(\mathrm{t}$, $J=5.7 \mathrm{~Hz}, 2 \mathrm{H}), 2.52(\mathrm{t}, J=7.2 \mathrm{~Hz}, 2 \mathrm{H}), 2.05-1.84(\mathrm{~m}, 2 \mathrm{H}), 1.72-1.60(\mathrm{~m}, 2 \mathrm{H}) .{ }^{13} \mathrm{C}$ NMR (free amine, $100 \mathrm{MHz}, \mathrm{CDCl}_{3}$ ) $\delta 147.56,147.24,142.89,137.40,136.68,126.48,126.27$, $126.14,125.10,121.93,120.05,119.76,119.70,111.39,109.80,109.75,109.51,107.55$, $57.65,55.94,55.91,55.72,51.06,46.23,28.64,28.14,24.58$. HRMS (TOF ES+) calcd for $\mathrm{C}_{27} \mathrm{H}_{31} \mathrm{~N}_{2} \mathrm{O}_{3}[\mathrm{M}+\mathrm{H}]^{+}$431.2335, found 431.2356.

\subsection{Pharmacology}

In vitro competition binding assays were performed as follows. Preparation of rat brain membrane and binding assays for the $\sigma_{1}$ and $\sigma_{2}$ receptor were performed using methods published previously in detail [30-34]. In brief, homogenates of whole rat brain excluding the cerebellum $(400-500 \mu \mathrm{g})$ were taken in test tubes and incubated with $5 \mathrm{nM}\left[{ }^{3} \mathrm{H}\right](+)-$ pentazocine to label $\sigma-1$ receptors, or $3 \mathrm{nM}\left[{ }^{3} \mathrm{H}\right]-\mathrm{DTG}$ in the presence of $300 \mathrm{nM}(+)-$ pentazocine to label $\sigma-2$ receptors. Non-specific binding was determined in the presence of $10 \mu \mathrm{M}$ haloperidol. Ten concentrations of each sigma compound ranging from 0.1-1000 $\mathrm{nM}$ were incubated for $120 \mathrm{~min}$ at $25^{\circ} \mathrm{C}$ in $50 \mathrm{mM}$ Tris- $\mathrm{HCl}, \mathrm{pH} 8.0$ to measure their ability to displace the radioligands from their binding sites. The total reaction volume was $500 \mu$. The assay was terminated by the addition of $5 \mathrm{ml}$ ice-cold $10 \mathrm{mM}$ Tris-HCl, $\mathrm{pH} 8.0$, followed by two washes through glass fiber filters presoaked in $1 \%$ polethyleneimine for at least $45 \mathrm{~min}$ to minimize non-specific binding. Both these assays were run in duplicate. Counts were extracted from the filters using Ecoscint (National Diagnostics, Manville, NJ) for at least $8 \mathrm{~h}$ prior to counting. $K_{\mathrm{i}}$ values were calculated using the Cheng-Prusoff equation [35].

\section{Acknowledgments}

This project was supported by grants from The National Institute on Drug Abuse (DA023205, DA013978). The National Institute on Drug Abuse arranged for the in vitro receptor and transporter assays at Oregon Health and Science University (OHSU) and for the Novascreen assays through contractual agreement with the vendors. 


\section{References and notes}

1. Quirion R, Bowen WD, Itzhak Y, Jumien JL, Musacchio JM, Rothman RB, Su TP, Tam SW, Taylor DP. Trends Pharmacol Exp Ther. 1992; 13:85-86.

2. Hanner M, Moebius FF, Flandorfer A, Knaus HG, Striessnig J, Kempner E, Glossmann H. Proc Natl Acad Sci USA. 1996; 93:8072-8077. [PubMed: 8755605]

3. Seth P, Fei YJ, Li HW, Huang W, Leibach FH, Ganapathy V. J Neurochem. 1998; 70:922-931. [PubMed: 9489711]

4. Matsumoto, RR. Sigma receptors: historical perspective and background. In: Matsumoto, RR.; Bowen, WD.; Su, TP., editors. Sigma receptors: chemistry, cell biology and clinical implications. Springer; New York: 2007. p. 1-23.

5. Bourrie B, Bribes E, Derocq JM, Vidal H, Casellas P. Curr Opin Invest Drugs. 2004; 5:1158-1163.

6. Volz HP, Stoll KD. Pharmacopsychiatry. 2004; 37:S214-S220. [PubMed: 15547788]

7. Maurice T, Su TP. Pharmacology \& Therapeutics. 2009; 124:195-206. [PubMed: 19619582]

8. Sanchez C, Arnt J, Costall B, Kelly ME, Meier E, Naylor RJ, Perregaard J. J Pharmacol Exp Ther. 1997; 283:1323-1332. [PubMed: 9400007]

9. Villard V, Espallergues J, Keller E, Alkam T, Nitta A, Yamada K, Nabeshima T, Vamvakides A, Maurice T. Neuropsychopharmacology. 2009; 34:1552-1566. [PubMed: 19052542]

10. Guitart X, Codony X, Monroy X. Psychopharmacology. 2004; 174:301-319. [PubMed: 15197533]

11. Matsumoto RR, Liu Y, Lerner M, Howard EW, Brackett DJ. Eur J Pharmacol. 2003; 469:1-12. [PubMed: 12782179]

12. Maurice T, Martin-Fardon R, Romieu P, Matsumoto RR. Neurosci Biobehav Rev. 2002; 26:499_ 527. [PubMed: 12204195]

13. Choi SR, Yang B, Plossl K, Chumpradit S, Wey SP, Acton PD, Wheeler K, Mach RH, Kung HF. Nucl Med Biol. 2001; 28:657-666. [PubMed: 11518647]

14. Vilner BJ, John CS, Bowen WD. Cancer Res. 1995; 55:408-413. [PubMed: 7812973]

15. Rowland DJ, Tu Z, Xu J, Ponde D, Mach RH, Welch MJ. J Nucl Med. 2006; 47:1041-1048. [PubMed: 16741315]

16. Tu Z, Xu J, Jones LA, Li S, Dumstorff C, Vangveravong S, Chen DL, Wheeler KT, Welch MJ, Mach RH. J Med Chem. 2007; 50:3194-3204. [PubMed: 17579383]

17. Mach RH, Smith CR, al-Nabulsi I, Whirett BR, Childers SR, Wheeler KT. Cancer Res. 1997; 57:156-161. [PubMed: 8988058]

18. Ostenfeld MS, Fehrenbacher N, Hoyer-Hansen M, Thomsen C, Farkas T, Jaattela M. Cancer Res. 2005; 65:8975-8983. [PubMed: 16204071]

19. Crawford KW, Bowen WD. Cancer Res. 2002; 62:313-322. [PubMed: 11782394]

20. Narayanan S, Bhat R, Mesangeau C, Poupaert JH, McCurdy CR. Future Med Chem. 2011; 3:7994. [PubMed: 21428827]

21. Maeda DY, Williams W, Bowen WD, Coop A. Bioorg Med Chem Lett. 2000; 10:17-18. [PubMed: 10636233]

22. Maier CA, Wunsch B. J Med Chem. 2002; 45:4923-4930. [PubMed: 12383018]

23. Yous S, Wallez W, Belloir M, Caignard DH, McCurdy CR, Poupaert JH. Med Chem Res. 2005; $14: 158-168$.

24. Gassiot AC, Charton J, Girault-Mizi S, Gilleron P, Debreu-Fontaine MA, Sergheraert C, Melnyk P. Bioorg Med Chem Lett. 2005; 15:4828-4832. [PubMed: 16140009]

25. Hajipour AR, Fontanilla D, Chu UB, Arbabian M, Ruoho AE. Bioorg Med Chem. 2010; 18:43974404. [PubMed: 20493718]

26. Perregaard J, Moltzen EK, Meier E, Sanchez C. J Med Chem. 1995; 38:1998-2008. [PubMed: 7783131]

27. Mach RH, Huang Y, Freeman RA, Wu L, Vangveravong S, Luedtke RR. Bioorg Med Chem Lett. 2004; 14:195-202. [PubMed: 14684327] 
28. Mesangeau C, Narayanan S, Green AM, Shaikh J, Kaushal N, Viard E, Xu YT, Fishback JA, Poupaert JH, Matsumoto RR, McCurdy CR. J Med Chem. 2008; 51:1482-1486. [PubMed: 18278854]

29. Standard conditions for Suzuki were followed ; see for example: Jacquemard U, Routier S, Dias N, Lansiaux A, Goossens JF, Bailly C, Merour JY. Eur J Med Chem. 2005; 40:1087-1095. [PubMed: 15951061]

30. Nguyen EC, McCracken KA, Liu Y, Pouw B, Matsumoto RR. Neuropharmacology. 2005; 49:638645. [PubMed: 15939443]

31. Matsumoto RR, Bowen WD, Tom MA, Vo VN, Truong DD, De Costa BR. Eur J Pharmacol. 1995; 280:301-10. [PubMed: 8566098]

32. Matsumoto RR, Shaikh J, Wilson LL, Vedam S, Coop A. Eur Neuropsychopharmacol. 2008; 18:871-81. [PubMed: 18755577]

33. Matsumoto RR, Pouw B. Eur J Pharmacol. 2000; 401:155-160. [PubMed: 10924920]

34. Fishback JA, Mesangeau C, Poupaert JH, McCurdy CR, Matsumoto RR. Eur J Pharmacol. 2011; 653:1-7. [PubMed: 21130085]

35. Cheng Y, Prusoff WH. Biochem Pharmacol. 1973; 22:3099-108. [PubMed: 4202581] 


\section{Research highlights}

- Preparation and evaluation of a series of indoles as sigma receptor ligands

- Identification of several sigma-2 selective derivatives

- Extensive pharmacological profile characterization for the best compound 


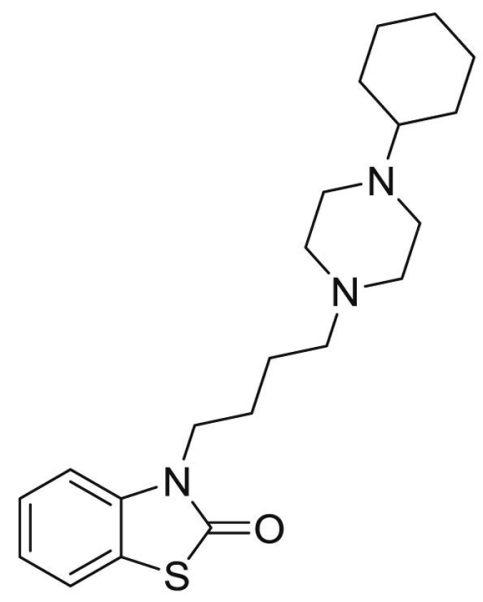

1

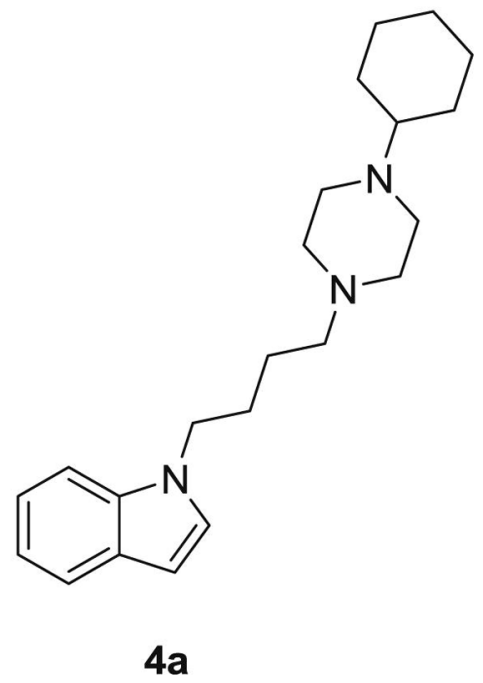

Figure 1.

Structures of $\mathbf{1}$ and its indole analogue $\mathbf{4 a}$ 
<smiles>CN1CCN(C2CCCCC2)CC1</smiles><smiles>CN1CCN(c2ccc(F)cc2)CC1</smiles><smiles>COc1cc2c(cc1OC)CN(C)CC2</smiles>

$\mathrm{R}^{2}$-rings<smiles>[Al]c1ccccc1</smiles><smiles>CC(C)(C)c1ccc(F)cc1</smiles><smiles>CC(C)(C)C1C=COC1</smiles>

$\mathrm{R}^{3}$-rings

Figure 2.

R2- and R3-rings 


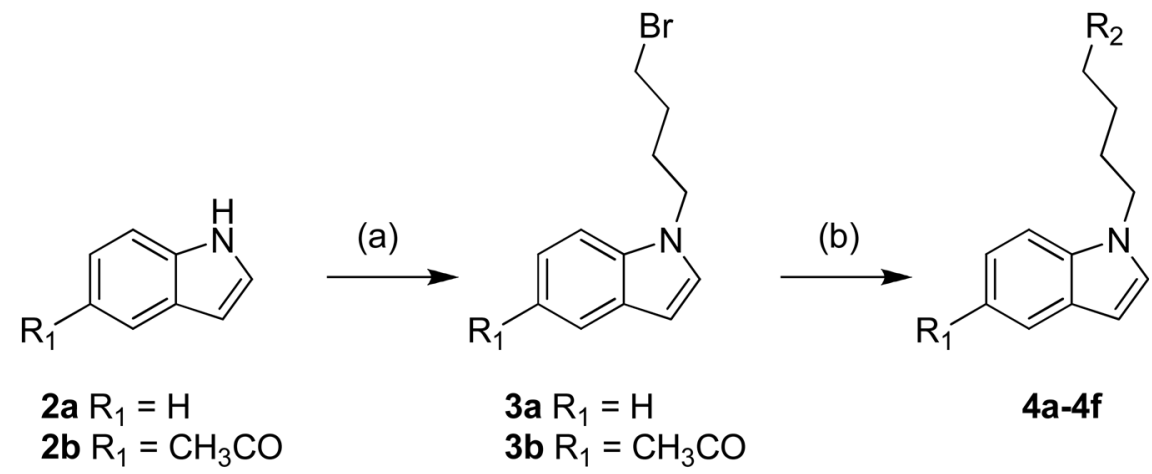

Scheme 1.

Synthesis of indole derivatives4a-4f. Reagents and conditions: (a) 1,4-dibromobutane, $\mathrm{KOH}, \mathrm{TBAI}, \mathrm{DMF}, 0^{\circ} \mathrm{C} \rightarrow \mathrm{rt}, 2 \mathrm{~h}$; (b) Cyclic amine, $\mathrm{K}_{2} \mathrm{CO}_{3}$, DMF, $60^{\circ} \mathrm{C}, 2 \mathrm{~h}$. 
<smiles>O=S(=O)(c1ccccc1)n1cc(Br)c2ccccc21</smiles>

5<smiles>[R3]c1cn(CCCCBr)c2ccccc12</smiles>

$8 a-8 c$ (a)<smiles>[R3]c1cn(S(=O)(=O)c2ccccc2)c2ccccc12</smiles>

$6 a-6 c$ (b)<smiles>[R3]c1c[nH]c2ccccc12</smiles>

7a-7c<smiles>[R2]CCCCn1cc([R3])c2ccccc21</smiles>

9a-9i

\section{Scheme 2.}

Synthesis of 3-substituted-indole derivatives. Reagents and conditions: (a) Arylboronic acid, $\mathrm{K}_{2} \mathrm{CO}_{3}, \mathrm{Pd}\left(\mathrm{P} \varphi_{3}\right)_{4}$, benzene/EtOH, reflux, 16 h; (b) $\mathrm{Mg}, \mathrm{NH}_{4} \mathrm{Cl}$, MeOH/THF, rt, $2 \mathrm{~h}$; (c) 1,4dibromobutane, $\mathrm{KOH}$, TBAI, DMF, $0^{\circ} \mathrm{C} \rightarrow \mathrm{rt}, 2 \mathrm{~h}$; (d) Cyclic amine, $\mathrm{K}_{2} \mathrm{CO}_{3}$, DMF, $60^{\circ} \mathrm{C}, 2$ h. 


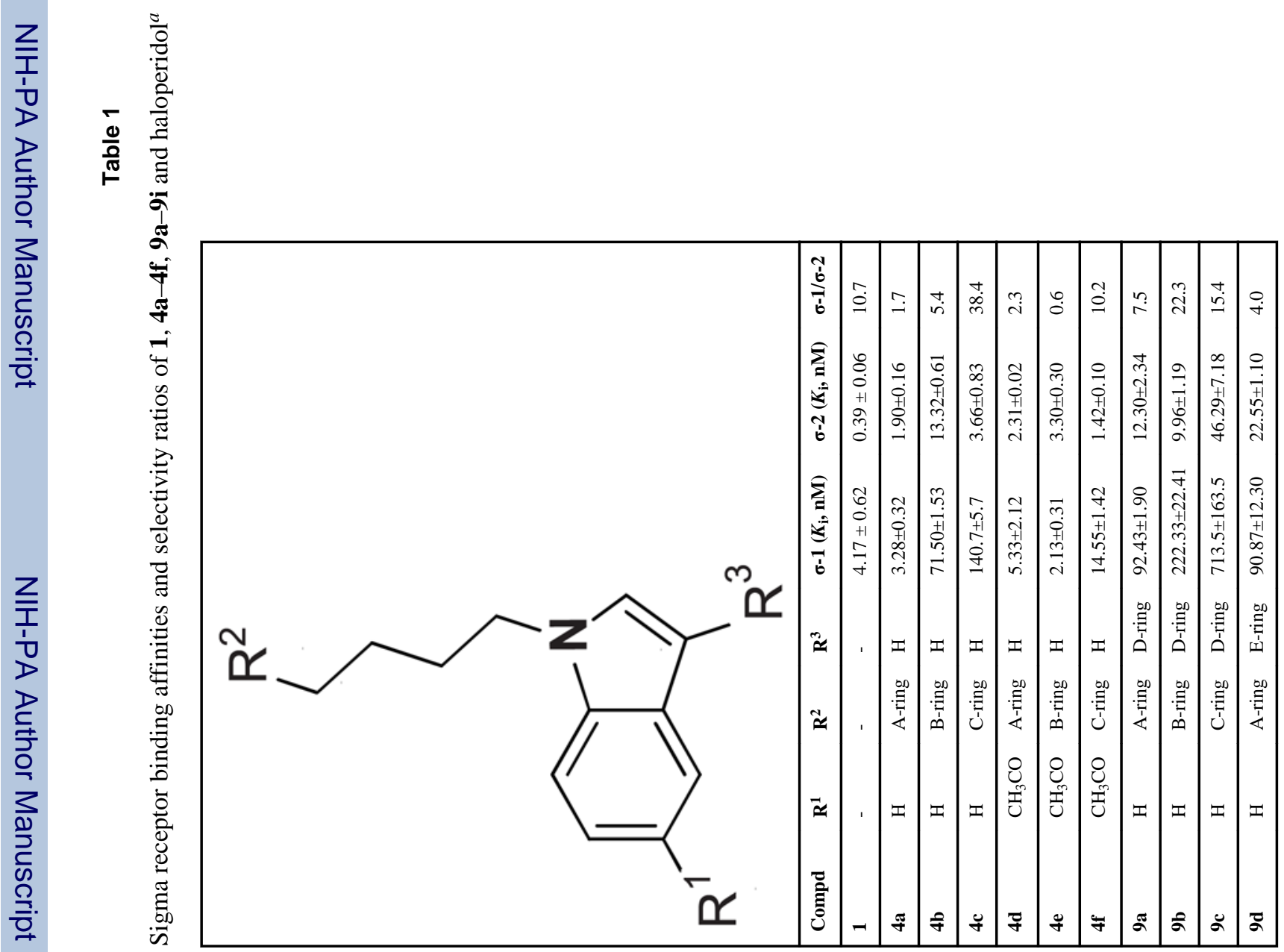

Eur J Med Chem. Author manuscript; available in PMC 2012 October 1. 


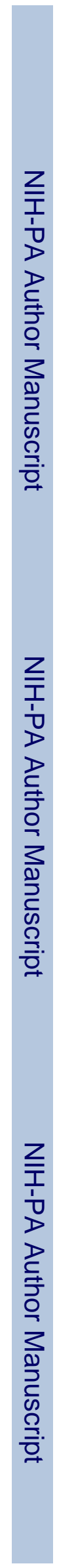




\section{Table 2}

Nonsigma protein binding affinities of compound $9 \mathbf{f}^{a}$

\begin{tabular}{|c|c|c|c|}
\hline & Radioligand & Nonspecific binding & $K_{\mathrm{i}}(\mathrm{nM})$ \\
\hline \multicolumn{4}{|c|}{ Monoamine Transporters } \\
\hline Dopamine $^{b}$ & $40-80 \mathrm{pM}\left[{ }^{125} \mathrm{I}\right] \mathrm{RTI}-55$ & $5 \mu \mathrm{M}$ mazindol & $5000 \pm 1000$ \\
\hline Serotonin $b$ & $40-80 \mathrm{pM}\left[{ }^{125} \mathrm{I}\right] \mathrm{RTI}-55$ & $5 \mu \mathrm{M}$ imipramine & $295 \pm 82$ \\
\hline Norepinephrine ${ }^{b}$ & $40-80 \mathrm{pM}\left[{ }^{125} \mathrm{I}\right] \mathrm{RTI}-55$ & $5 \mu \mathrm{M}$ mazindol & $1350 \pm 110$ \\
\hline \multicolumn{4}{|c|}{ Other Receptors } \\
\hline Dopamine $\mathrm{D}_{1}{ }^{c}$ & $0.18 \mathrm{nM}\left[{ }^{3} \mathrm{H}\right] \mathrm{SCH}-23390$ & $1 \mu \mathrm{M} \mathrm{SCH}-23390$ & $>10000$ \\
\hline Dopamine $\mathrm{D}_{2}{ }^{d}$ & $0.2-0.5 \mathrm{nM}\left[{ }^{3} \mathrm{H}\right] \mathrm{YM}-09151-2$ & $1 \mu \mathrm{M}$ chlorpromazine & $870 \pm 260$ \\
\hline Dopamine $\mathrm{D}_{3} d$ & $0.2-0.5 \mathrm{nM}\left[{ }^{3} \mathrm{H}\right] \mathrm{YM}-09151-2$ & $1 \mu \mathrm{M}$ chlorpromazine & $544 \pm 90$ \\
\hline Serotonin $5-\mathrm{HT}_{1 \mathrm{~A}} e$ & $0.5 \mathrm{nM}\left[{ }^{3} \mathrm{H}\right] 8-\mathrm{OH}-\mathrm{DPAT}$ & $1 \mu \mathrm{M}$ dihydroerotamine & $1510 \pm 410$ \\
\hline Serotonin $5-\mathrm{HT}_{2 \mathrm{~A}} e$ & $0.1 \mathrm{nM}\left[{ }^{125} \mathrm{I}\right] \mathrm{DOI}$ & $10 \mu \mathrm{M} 5-\mathrm{HT}$ & $1270 \pm 310$ \\
\hline
\end{tabular}

${ }^{a}$ Affinities $\left(K_{\mathrm{i}}\right.$ in $\left.\mathrm{nM}\right)$ were determined using standard assays conditions. The values in this table represent the mean \pm SEM from replicate assays. Values of $>10000 \mathrm{nM}$ signify that there was less than $30 \%$ displacement of the radioligand at that concentration.

$b_{\text {HEK293 cells expressing hBAT, hSERT or hNERT. }}$

$c_{\text {LhD1 cells. }}$

${ }^{d}$ CHOp-D2 or CHOp-D3 cells.

${ }^{e}$ HEK-h5-HT1A or HEK-h5-HT2A cells. 
Table 3

Summary of binding profile of 9 f in 64 radioligand/enzyme assays at $10^{-5} \mathrm{M}$ and $10^{-7} \mathrm{M}^{a}$

\begin{tabular}{|lll|}
\hline Assay name & $\mathbf{5 0 \%}$ inhibition $\left(\mathbf{1 0}^{-\mathbf{7}} \mathbf{M}\right)$ & $\mathbf{5 0 \%}$ inhibition $\left(\mathbf{1 0}^{-\mathbf{5}} \mathbf{M}\right)$ \\
\hline Adrenergic, $\alpha 1$ & No & Yes \\
\hline Adrenergic, $\alpha 2$ & No & Yes \\
\hline Adrenergic, $\beta 1$ & No & No \\
\hline Cannabinoid, $\mathrm{CB}_{1}$ & No & Yes \\
\hline Cannabinoid, $\mathrm{CB}_{2}$ & No & Yes \\
\hline Dopamine $\mathrm{D}_{4.2}$ & Yes & Yes \\
\hline Glycine, Strychnine & No & Yes \\
\hline Histamine, $\mathrm{H}_{1}$ & No & Yes \\
\hline Histamine, $\mathrm{H}_{2}$ & No & Yes \\
\hline Muscarinic, $M 1$ & No & Yes \\
\hline Muscarinic, M2 & No & Yes \\
\hline Muscarinic, central & No & Yes \\
\hline Opioid, $\mu$ & No & Yes \\
\hline Calcium channel, type L $(\mathrm{BZT})$ & Yes \\
\hline Sodium, Site 2 & Yes \\
\hline Neurokinin, NK2 $(\mathrm{NKA} 0$ & Yes \\
\hline
\end{tabular}

${ }^{a}$ Details of each assay condition can be accessed through Caliper's web site at www.caliperls.com. 